
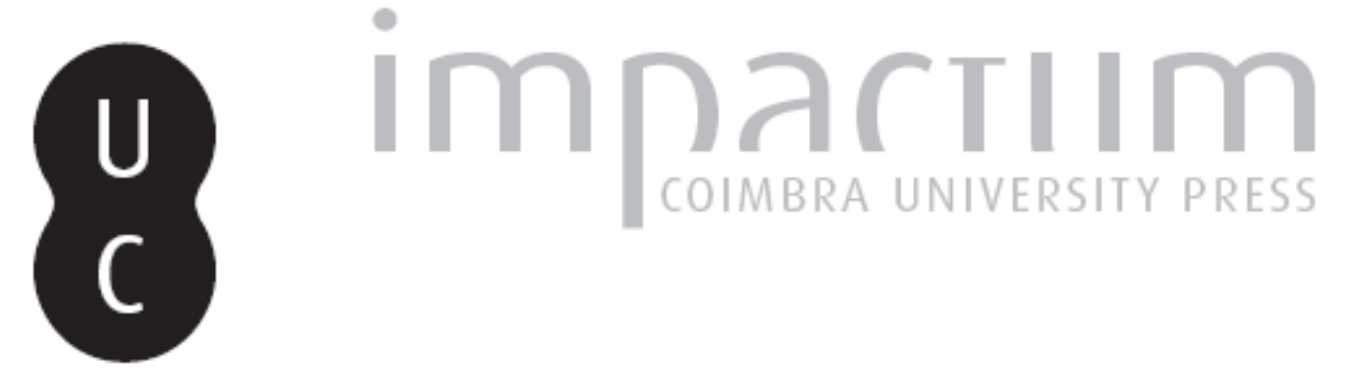

\title{
Um poeta entre dois idiomas
}

\section{Autor(es): $\quad$ Chorão, João Bigotte}

Publicado por: Imprensa da Universidade de Coimbra

URL persistente:

URl:http://hdl.handle.net/10316.2/42528

DOI:

DOI:https://doi.org/10.14195/0870-8584_5_15

Accessed : $\quad$ 26-Apr-2023 13:06:34

A navegação consulta e descarregamento dos títulos inseridos nas Bibliotecas Digitais UC Digitalis, UC Pombalina e UC Impactum, pressupõem a aceitação plena e sem reservas dos Termos e Condições de Uso destas Bibliotecas Digitais, disponíveis em https://digitalis.uc.pt/pt-pt/termos.

Conforme exposto nos referidos Termos e Condições de Uso, o descarregamento de títulos de acesso restrito requer uma licença válida de autorização devendo o utilizador aceder ao(s) documento(s) a partir de um endereço de IP da instituição detentora da supramencionada licença.

Ao utilizador é apenas permitido o descarregamento para uso pessoal, pelo que o emprego do(s) título(s) descarregado(s) para outro fim, designadamente comercial, carece de autorização do respetivo autor ou editor da obra.

Na medida em que todas as obras da UC Digitalis se encontram protegidas pelo Código do Direito de Autor e Direitos Conexos e demais legislação aplicável, toda a cópia, parcial ou total, deste documento, nos casos em que é legalmente admitida, deverá conter ou fazer-se acompanhar por este aviso.

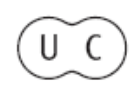




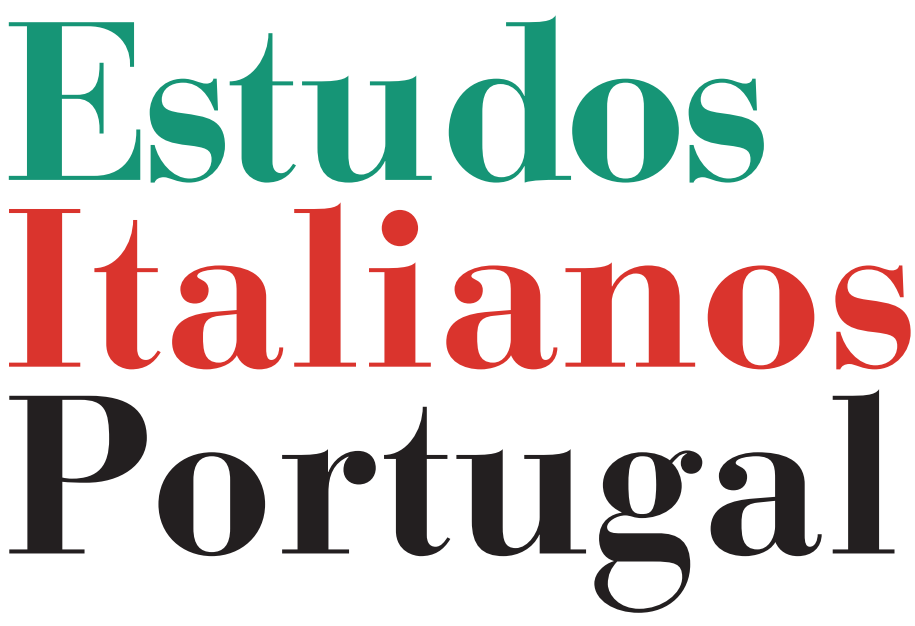

Instituto

Italiano

de Cultura

de Lisboa

Nova Série

$\mathrm{N}^{\mathbf{0}} 5$ 


\title{
UM POETA ENTRE DOIS IDIOMAS
}

\author{
JoÃo Bigotte Chorão*
}

"Leer versos no es una de mis tarehas habituales", confessou aquele brilhante espírito que foi Ortega y Gasset precisamente no prefácio a um livro de poesia. Mas há poetas que nos acompanham a vida toda, porque neles encontramos sempre a palavra que precisávamos de ouvir no silêncio. Camões é essa palavra que nos dá ânimo mesmo nos seus poemas mais dramáticos.

Com um dos grandes poetas da minha geração, António Osório, percorro a Grécia clássica, a Itália renascentista, a Espanha trágica, o mundo dos livros e o mundo da Criação.

Conhecemos da nossa história literária autores, e grandes autores, que escreveram simultaneamente em duas línguas - Gil Vicente, Camões, D. Francisco Manuel de Melo. O que se justifica não por motivos políticos ou imposição imperialista de nação estrangeira. No caso dos escritores referidos, o uso do castelhano deve-se sobretudo à circunstância geográfica e cultural de pertencerem ao grande espaço da Ibéria.

* Escritor e crítico, João Bigotte Chorão tem vindo a dedicar particular atenção ao diarismo, ao memorialismo e à epistolografia. Foi director literário da Editorial Verbo. É assíduo colaborador de várias revistas e autor de numerosos prefácios e estudos. De entre as suas obras em volume, recordem-se as mais recentes, O essencial sobre Tomaz de Figueiredo (2000); Galeria de retratos (2000); Diário quase completo (2001; Grande Prémio de Literatura Biográfica APE/C); e O Espírito da Letra (2004). 
A confusão de línguas de Babel pode entender-se como o caos nascido de um idioma que, pretendendo-se universal, acabou por ser uma algaraviada ininteligível. No confuso mundo do século XX, assistiu-se a guerras que foram também ideológicas, a totalitarismos que anexaram e esmagaram nações. Nem a língua chegou a escapar ao escopo hegemónico. Aqui ao lado, o castelhano impôs-se ao galego e ao catalão, línguas aliás de uma boa tradição literária. No Leste europeu, a sorte das armas ditou a "russificação" de vários países em que, se não foram proibidas as línguas nacionais, se tornou obrigatório o estudo do russo. Escritores daquele vasto espaço, privados da liberdade física quando não da liberdade espiritual que lhes interditava a publicação dos seus livros, viram-se coagidos, se porventura abertas as portas do cárcere e passadas as fronteiras, a exprimir-se em outra língua que não a sua, de circulação só intra muros. Polacos, húngaros, romenos, checos, albaneses - para não falar de russos foram forçados a recorrer a uma língua estrangeira de maior universalidade.

Diríamos, regressando a Portugal, que nem sequer a língua escapou à solicitude oficial, como se ela fosse objecto de decreto. Não são os governos que fazem a língua, mas os escritores que sabem do seu ofício, e é o povo que ainda a fala com genuíno sabor. Depois deste arrazoado que parece despropositado mas não é, falemos de António Osório, que tem com a língua uma relação complexa, quer por via materna, quer por via paterna. Não que ele seja bilingue, já que portuguesa é a sua língua literária.

Acontece que nascido em Portugal e de pai português, lhe coube ser filho de mãe italiana - eu diria mesmo florentina. De tal modo Florença, cidade como nenhuma outra admirável, é berço de todas as artes - pintura, escultura, arquitectura, poesia. A esse título, ninguém lhe pode negar o de capital do Renascimento. 
António Osório não nasceu em Florença, mas Florença estava-lhe no sangue e no espírito. Por obra e graça de sua mãe, senhora de singular cultura para a época. Com o dom da vida, deve-lhe o gosto da língua, que aprendeu precocemente nas leituras que a mãe fazia de Dante. Por seu lado o pai, advogado como seria o filho e foram outros membros de uma família de juristas e de letrados - Ana de Castro Osório, Alberto de Castro Osório, João de Castro Osório, José Osório de Oliveira -, o pai, dizia, não limitou o horizonte à letra dos códigos, mas abriu a sua inteligência e a sua sensibilidade ao universo da palavra. Na idade de formação, e pela mão de seu pai, Camões veio complementar a lição materna de Dante. Na ligação da família Osório de Castro com a literatura, como esquecer o papel que ela teve em podermos conhecer a poesia de Camilo Pessanha, esse milagre de subtileza musical.

O exercício activo da advocacia não lhe deixou grande tempo para se entregar mais à poesia e à recolha em livro e seleccionar os seus primeiros poemas. Data de 1972 a sua estreia em livro, A Raiz Afectuosa, uma estreia não precoce, mas já segura. Entretanto, o autor havia incorporado na sua cultura, depois dos clássicos italianos, clássicos contemporâneos como Montale, Ungaretti, Saba, com a sua poesia mais hermética ou mais dorida. Um poema de António Osório tem mesmo o título de um livro de Ungaretti, La terra promessa. Torcendo o pescoço à eloquência carducciana, Osório, a exemplo de Ungaretti, restitui ao verbo a sua nudez essencial e todavia densa de sentido: Immagazzinare sofferenza.//Distribuirla quindi//limpida.

Também a música e a pintura são importantes na mundivisão de António Osório, que dedica todo um poema à "felicidade da pintura". Não é, para Dante, a pintura visibile parlare? Os seus pintores são, entre os italianos, Uccello, Leonardo, Modigliani, e, dos espanhóis, Velásquez e Goya, e o flamengo Bosch. 
Poeta não bilingue, a ascendência italiana de António Osório e a presença da Itália na sua obra, era natural que alguém se interessasse por um autor com essas raízes. Assim, em 1986, Carlo Vittorio Cataneo traduziu Décima Aurora, para a qual escreveu uma introdução. Data de 2004 a tradução de Bestiário. Mais recente (2008) Marco Bruno traduziu A Ignorância da Morte, que fez preceder de um longo estudo. Eis, já em 2009, a antologia organizada por Guia Boni, com o título de Torno con te a Ulisse, um verso aliás do próprio António Osório n' A Ignorância da Morte, com uma breve apresentação da tradutora. Neste florilégio, assim lhe chama Guia Boni, pode o leitor cotejar o original com a tradução.

Creio já ter dito um dia que ler em italiano António Osório é como um acto de restituição à língua materna. A mãe está presente, omnipresente na memória sentimental e na poesia, que a celebra e o seu mundo: "Madre, che amavo come Firenze,/la tua lingua, cipressi,/ulivi, bianchi buoi $[\ldots]$ ". Ou então o lamento de quem se confessa dividido entre dois mundos e dois idiomas: "Sin da bambino mi hai costretto/a parlare la tua língua./Italia, religione tua, puoi/mia, Mamma, che a fin de bene/me hai frantumato, lasciandomi/senza patria alcuna". Ainda esta evocação florentina: "Come un colombo di Piazzale Michelangelo/volo, strada per strada, nel cielo di Firenze./Cerco di arrivare al tetto,/alla distrutta casa dei tuoi genitori. [...] $\mathrm{E}$ in attesa che una persiana si apra/e trovi, Mamma, un volto che ricordi il tuo/e su quella mano io giunga e mangi”.

E da Crónica da Fortuna extraio este texto tão expressivo da ambivalência para uma criança nascida, digamos assim, no seio de duas línguas maternas: "[...] eu tinha sempre comigo duas palavras, a portuguesa e a italiana, vizinhas, mas ciosas 
de si, exigentes e qualquer delas inconciliável; esse era o meu segredo e, às vezes, infortúnio. Porque o meu italiano, por mais que minha mãe fizesse, não era perfeito. Um dia, em Florença, devia eu ter quatro anos, acompanhado de meu pai, falei num jardim para garotos como eu - queria entrar no jogo. E eles riram-se, porque instilara no pedido um timbre ou uma palavra vindos da minha terra. Também o pai se riu. Foi essa a minha primeira lição de italiano: não é dado ter duas línguas maternas. A da pátria conta mais que a da mãe."

Torno con te a Ulisse... Ulisses é uma referência constante, imagem da partida, da viagem, da aventura, do regresso, do reencontro da casa e da mulher que espera, espera sempre com paciência.

Contrariando a alegação de ateísmo do poeta, eu vejo nele um sentimento de pietas que abraça fraternalmente tudo e todos, os homens e as coisas, os animais e as plantas, num como Cântico das Criaturas. O amor da Criação é o outro nome que podemos dar à Beleza - e na Beleza, como proclamou a voz profética de Dostoievski, nela, e só nela, põe o homem a esperança na salvação do Mundo. 